\title{
Linagliptin as add-on therapy to insulin for patients with type 2 diabetes
}

This article was published in the following Dove Press journal:

Vascular Health and Risk Management

31 October 2013

Number of times this article has been viewed

\section{Karoline von Websky Christoph Reichetzeder Berthold Hocher \\ Institute of Nutritional Science, University of Potsdam, Potsdam- Rehbrücke, Germany}

Correspondence: Berthold Hocher Universität Potsdam, Institut für Ernährungswissenschaften, Professur Experimentelle Ernährungsmedizin, Arthur-Scheunert-Allee I I4-I I6, D-14558 Nuthetal, Germany Tel +4933200885508 Fax +49 3320088 554I Email hocher@uni-potsdam.de

\begin{abstract}
Type 2 diabetes mellitus (T2DM) is a highly prevalent, progressive disease that often is poorly controlled. The combination of an incretin-based therapy and insulin is a promising approach to optimize the management of glycemic control without hypoglycemia and weight gain. Linagliptin, a recently approved oral dipeptidyl peptidase-4 inhibitor, has a unique pharmacological profile. The convenient, once-daily dosing does not need adjustment in patients with hepatic and/or renal impairment. In clinical studies linagliptin shows an important reduction of blood glucose with an overall safety profile similar to that of placebo. So far, the combination of linagliptin and insulin has been tested in three major clinical studies in different populations. It has been shown that linagliptin is an effective and safe add-on therapy to insulin in patients with T2DM. The efficacy and safety of this combination was also shown in vulnerable, elderly T2DM patients and in patients with T2DM and renal impairment. Favorable effects regarding the counteraction of hypoglycemia make linagliptin especially interesting as an add-on therapy to insulin. This review aims to present the existing clinical studies on the efficacy and safety of linagliptin as add-on therapy to insulin in patients with T2DM in the context of current literature. Additionally, the possible advantages of linagliptin as an add-on therapy to insulin in relation to cardiovascular safety, patient-centered therapy and the prevention of hypoglycemia, are discussed.
\end{abstract}

Keywords: incretin, dipeptidyl peptidase-4, glucagon like peptide-1, glycemic control, renal impairment, hypoglycemia

\section{Introduction}

Three clinical trials have been conducted to date in order to evaluate the efficacy and safety of linagliptin as add-on therapy to insulin, in patients with type 2 diabetes (T2DM) (see Table 2). ${ }^{1-3}$ These studies have indicated that the addition of linagliptin to insulin improves glycemic control, without increasing the risk of hypoglycemia. An additional advantage of linagliptin is that no dose adjustment in elderly patients or in patients with impaired renal function is necessary. In this paper, we give an overview of these three studies and discuss their results in the context of the current literature. In the short introduction, the rationale and the background for an add-on therapy to insulin is explained. The studies on linagliptin as add-on therapy to insulin in patients with T2DM are presented individually and discussed in comparison with equivalent studies of other dipeptidyl peptidase-4 (DPP-4) inhibitors. Furthermore, important aspects of diabetes therapy, namely cardiovascular safety, patient-centered therapy, and hypoglycemia are considered in the context of the presented data.

We searched ClinicalTrials.gov for clinical trials with linagliptin and insulin, using the search term "linagliptin insulin." Of the six trials found, three were excluded from 
the review because their inclusion criteria did not comprise insulin treatment of the patients. We then searched PubMed for publications of the aforementioned clinical trials. Two of the identified studies investigated were already published. A manuscript of the third was obtained from the author and is yet to be published. In order to obtain background information for the introduction and discussion, a PubMed search was performed using the terms "type 2 diabetes," "dipeptidyl peptidase-4," "insulin," and various synonyms. Reference lists in selected articles were also reviewed to identify additional relevant information. Publications from the American Diabetes Association and the US Food and Drug Administration (FDA), manufacturers' prescribing information, and posters from scientific congresses were considered and are cited.

This review is not a classical systematic review. There are only three studies on linagliptin as add-on therapy to insulin in patients with T2DM. Further long-term and comparative efficacy and tolerability data are required, to gather substantial knowledge on the prolonged use of linagliptin in addition to insulin: The differences in the existing studies regarding study design and patient populations are limiting factors when comparing their results. Most importantly, the effectiveness of translating evidence into routine practice has yet to be provided.

\section{Background of add-on therapy to insulin for the treatment of type 2 diabetes}

The importance of maintaining glycemic levels in diabetes as close as possible to normoglycemia is well known. This reduces the risk of microvascular diabetic complications and slows the progression of other complications, like nephropathy, retinopathy, and neuropathy. ${ }^{4}$ Thus, a primary aim of diabetes management is the achievement and maintenance of normoglycemia while simultaneously minimizing the risk of adverse events, like hypoglycemia and weight gain. Despite many enhancements in treatment options, only $50 \%$ to $60 \%$ of patients with T2DM achieve their glycemic goals. ${ }^{5}$ This emphasizes the need for a better understanding and managing of the disease. The guidelines from the American Diabetes Association recommend therapy with metformin or sulfonylurea as a first-line antihyperglycemic treatment for most patients; with disease progression, a second and third oral antidiabetic drug (OAD) need to be added ${ }^{6}$ Relatively new OADs are glucagon-like peptide-1 receptor (GLP-1R) agonists and DPP-4 inhibitors. Substances from both classes fall into the category of incretin-based therapy, which has become increasingly important in the treatment of T2DM.

The rationale for an incretin-based therapy is the role of endogenous glucoregulatory peptide hormones (incretins) in the pathophysiology of T2DM. In response to food intake, incretins, such as glucagon-like peptide-1 (GLP-1) and glucose-dependent insulinotropic polypeptide (GIP), are secreted from intestinal cells. By enhancing insulin secretion and reducing glucagon secretion from the pancreatic alpha and beta cells in a glucose-dependent manner, they lower plasma glucose and regulate postprandial glucose homeostasis. ${ }^{7}$ At pharmacologic concentrations, GLP-1 delays gastric emptying. ${ }^{8}$ In vivo, GLP-1 and GIP are degraded by the serine protease DPP- $4 .{ }^{9}$ Reversible inhibition of DPP-4 with DPP-4 inhibitors results in higher levels of active incretins. This in turn leads to an increased synthesis of insulin, thus improving glycemic control. In a consensus statement of the American Association of Clinical Endocrinologists/American College of Endocrinology, DPP-4 inhibitors were recommended as one possible monotherapy option for patients with an initial glycated hemoglobin $\left(\mathrm{HbA}_{1 \mathrm{c}}\right)$ of $6.5 \%$ to $7.5 \%$; when the initial $\mathrm{HbA}_{1 \mathrm{c}}$ is $\geq 7.6 \%$, one possible treatment option is the combination of DPP-4 inhibitors with other OADs. ${ }^{10}$ The clinical guidelines from The National Institute for Health and Clinical Excellence mention DPP-4 inhibitors as secondline therapy instead of sulfonylurea agents in patients at significant risk for hypoglycemia and its complications. ${ }^{11}$ In fact, the application of DPP-4 inhibitors is already part of many different antihyperglycemic treatment regimens, from monotherapy to dual and triple therapy in combination with other agents. With chronic progression of T2DM in many patients, a declining glycemic control over time can become evident despite adequate diet, exercise, and therapy with OADs. ${ }^{12-14}$ Within a few years, treatment intensification is required because of a progressive loss of beta cells and the diminishing secretory capacity of the remaining cells. ${ }^{15}$ Eventually, the initiation of insulin therapy is necessary in order to maintain glycemic control. For patients with severe hyperglycemia at diagnosis, there is clear evidence that an early use of insulin will bring a clinically relevant benefit by improving beta cell function, making long-term control of diabetes easier. ${ }^{16,17}$ Besides its effects on glucose levels, insulin also regulates triglyceride levels in the plasma. Especially in patients with poor glycemic control, insulin therapy may have beneficial effects on hypertriglyceridemia. ${ }^{18}$ However, insulin therapy alone can scarcely address the multiple pathophysiologic aspects of T2DM. A combination with 
other medications can be favorable in order to achieve synergistic effects. Combining insulin with incretin-based therapy displays certain clinical advantages: Incretins have complementary effects to insulin with respect to fasting and postprandial glucose control. While basal insulin therapy primarily targets elevated fasting glycemia, incretins mainly improve postprandial glycemia by increasing the sensitivity and responsiveness of pancreatic alpha and beta cells to glucose. ${ }^{19,20}$ This is especially interesting, since in patients treated with insulin, beta cell mass and function are usually already significantly decreased. Evidence from animal experiments indicates that incretins may increase beta cell mass and alter the disease progression of diabetes. ${ }^{21,22}$ In humans, treatment with sitagliptin has been shown to improve measures of beta cell function. ${ }^{17}$ The combination of sitagliptin and metformin as an initial therapy was shown to enhance the responsiveness of pancreatic beta cells to glucose in both fasting and postprandial states, in patients with T2DM. ${ }^{23}$ However, the insulin-releasing effect of incretins is likely to decline when the preservation of beta cell mass cannot be maintained during further disease progression. ${ }^{24}$ This underlines the significance of the combination of insulin and incretin-based therapy. By combining insulin with a GLP-1R agonist or a DPP-4 inhibitor, the dose of insulin can be kept low, still achieving good glycemic control. ${ }^{25}$

GLP-1R agonists and DPP-4 inhibitors have both been proven effective, with acceptable tolerability profiles. ${ }^{26}$ Concerns about an increased risk of pancreatitis and pancreatic cancer were not confirmed by a large meta-analysis of 53 trials, as treatment with DPP-4 inhibitors was not associated with an increased risk of pancreatitis or malignancies. ${ }^{27}$ The recently published joint statement of the American Diabetic Association, the European Association for the Study of Diabetes and the International Diabetes Federation declared there were no concerns for pancreatic disease with incretin therapy. ${ }^{28}$

A strong scientific rationale suggests that DPP-4 inhibitors can prevent or counteract hypoglycemia. This is especially important for the management of insulin-treated patients since the limiting factor in this population is iatrogenic hypoglycemia. ${ }^{29}$ The insulinotropic effects of incretins are glucose-dependent and decline as postprandial serum glucose levels return to normal ranges. The incretin GIP increases glucagon levels during fasting and hypoglycemic conditions, while potentiating glucose-induced insulin secretion during hyperglycemia. ${ }^{30}$ Especially in critical patient populations, the combination of DPP-4 inhibitors with basal insulin can be recommended to minimize the risk of hypoglycemia. ${ }^{31} \mathrm{In}$ addition, the weight gain associated with an increasing insulin dose can be avoided by combining insulin with incretin-based therapy. ${ }^{25,32}$ Table 1 summarizes the respective advantages and disadvantages of insulin and incretin-based therapy and their combination.

Linagliptin is one of the newest DPP-4 inhibitors, it has a xanthene-based structure and unique pharmacological properties. ${ }^{33}$ The in vitro potency of linagliptin, expressed as half the minimal inhibitory concentration (IC50), is approximately $1 \mathrm{nM}$. This is several times higher than that of other DPP-4 inhibitors, with $19 \mathrm{nM}$ for sitagliptin, $24 \mathrm{nM}$ for alogliptin, $50 \mathrm{nM}$ for saxagliptin, and $62 \mathrm{nM}$ for vildagliptin. The in vitro selectivity of linagliptin is also very good, being 10,000-fold higher for DPP-4 than for other DPPs, such as DPP-2, DPP-8, and DPP-9. Only alogliptin has a comparable in vitro selectivity. ${ }^{34}$ Linagliptin has a high affinity for binding to DPP-4 in plasma and tissues, where the enzyme is bound to membranes. Therefore, the terminal half-life of the substance is long ( $>100$ hours). ${ }^{35}$ Linagliptin received FDA approval as an oral glucose-lowering drug for the treatment of T2DM in May $2011^{36}$ after being extensively evaluated in clinical Phase 3 trials worldwide. A clinically meaningful glycemic efficacy of once daily $5 \mathrm{mg}$ linagliptin, as monotherapy or in combination with other OADs, has been shown in around 6,000 patients with T2DM. Further, an international linagliptin clinical trial program showed a similar safety and tolerability for the drug as with placebo. ${ }^{37}$ As linagliptin is primarily excreted via bile and the gut, a dose adjustment in patients with renal or hepatic dysfunction is not needed. ${ }^{38}$ In 2012 the US FDA approved a supplemental new drug application for linagliptin, for use as add-on therapy to insulin. ${ }^{36}$

\section{Efficacy and safety of linagliptin in combination with insulin in patients with type 2 diabetes}

The long-term efficacy and safety of the DPP-4 inhibitor linagliptin as add-on therapy to basal insulin alone or in combination with metformin and/or pioglitazone was evaluated in a multicenter, randomized, placebo-controlled, parallel group, Phase 3 study. ${ }^{3}$ A total of 1,261 patients with T2DM and insufficient glycemic control despite basal insulin treatment were enrolled. The patients were treated with $5 \mathrm{mg}$ linagliptin once daily for at least 52 weeks. The background dose of insulin was to remain stable (within 10\% of the baseline dose) during the first 24 weeks of treatment, with subsequent dose adjustment permitted according to the clinical judgment of the investigator. 
Significant improvement in glycemic control was achieved with additional linagliptin treatment compared with placebo, in patients with T2DM inadequately controlled on basal insulin alone or in combination with metformin and/or pioglitazone. $\mathrm{HbA}_{1 \mathrm{c}}$ was reduced and fasting plasma glucose levels improved in a clinically relevant way. At 24 weeks, the adjusted mean change from baseline in the linagliptin group was $-0.58 \%$ (standard error [SE] 0.08 ), compared with $0.07 \%$ (SE 0.08) in the placebo group. The treatment difference in $\mathrm{HbA}_{1 \mathrm{c}}$, as adjusted mean change from baseline, was $-0.65 \%$ (95\% confidence interval $[\mathrm{CI}]:-0.74$ to -0.55$)(P<0.0001)$ after 24 weeks, without additional risk of hypoglycemia or weight gain, for patients treated with linagliptin and insulin. After 52 weeks, the adjusted mean changes in $\mathrm{HbA}_{1 \mathrm{c}}$ from baseline were $-0.48 \%$ (SE 0.08 ) for linagliptin and $0.05 \%$ (SE 0.08) for placebo, resulting in a placebo-adjusted mean change in $\mathrm{HbA}_{1 \mathrm{c}}$ from baseline of $-0.53 \%$ (95\% CI: -0.64 to -0.43$)(P<0.0001)$. The treatment difference between linagliptin and placebo was maintained for 76 weeks. The difference between linagliptin and placebo in fasting plasma glucose as adjusted mean change from baseline at 24 weeks was $-0.6 \mathrm{mmol} / \mathrm{L}$ (95\% CI: -0.9 to -0.4$)(P<0.001)$. Among patients with baseline $\mathrm{HbA}_{1 \mathrm{c}} \geq 7.0 \%, 16 \%$ of patients in the linagliptin group and $7 \%$ of patients in the placebo group attained $\mathrm{HbA}_{1 \mathrm{c}}$ values $<7.0 \%$ after 24 weeks of treatment $(P<0.0001)$. The proportion of patients with a reduction in $\mathrm{HbA}_{1 \mathrm{c}} \geq 0.5 \%$ was higher in the linagliptin group (37\%) compared with the placebo group $(17 \%)(P<0.0001)$. The mean change of basal insulin dose up to week 24 was 0.1 IU (standard deviation [SD] 0.2) for patients treated with linagliptin and 0.4 IU (SD 0.2) for patients treated with placebo - until 24 weeks, the dose was to remain within
$10 \%$ of baseline. From week 24, when insulin titration was allowed and recommended, the mean basal insulin dose increased in the linagliptin group to a lesser extent than it did in the placebo group. The adjusted mean change from baseline in insulin dose at week 52 was 2.6 IU (SD 0.8) for linagliptin and 4.2 IU (SD 0.8) for placebo $(P<0.003)$. The safety analyses did not show any major concerns for treatment with linagliptin, as the overall incidence of patients with $\geq 1$ reported adverse event (AE) was comparable between the treatment groups. The observed incidence of hypoglycemia (investigator-defined hypoglycemic AEs) in patients treated with linagliptin was similar to that with placebo at week 24 (linagliptin: 22.0\%; placebo: 23.2\%) and at the end of treatment (linagliptin: $31.4 \%$; placebo: $32.9 \%$ ). The incidence of severe hypoglycemia was also similar between the groups (at week 24 , this was $0.3 \%$ in the linagliptin group and $0.6 \%$ in the placebo group; at the end of treatment, this was $1.7 \%$ for linagliptin and $1.1 \%$ for placebo).

In summary, the results of this trial showed that linagliptin is an effective and safe add-on therapy that can help patients on basal insulin to improve their blood sugar control without weight gain or additional risk of hypoglycemia. Other DPP-4 inhibitors have also been studied in large clinical trials, as add-ons to insulin. For vildagliptin, ${ }^{40}$ sitagliptin, ${ }^{41}$ and saxagliptin, ${ }^{42}$ an improved glycemic control was shown when added to ongoing insulin therapy. All three DPP-4 inhibitors were generally well tolerated in patients with T2DM. The results of these studies suggest that concomitant treatment with DPP-4 inhibitors and insulin is effective for achieving better glycemic control in patients with T2DM, while improving the safety and tolerability of the antihyperglycemic treatment.

Table I Advantages and disadvantages of treatment with insulin and incretins

\begin{tabular}{|c|c|c|}
\hline Advantages: insulin & Advantages: incretins & $\begin{array}{l}\text { Advantages: combination insulin } \\
\text { and linagliptin }\end{array}$ \\
\hline Most effective blood glucose-lowering therapy $y^{39}$ & Safe and effective improvement of glycemic control ${ }^{26}$ & Reduction of hypoglycemia risk ${ }^{30,31}$ \\
\hline Most clinical experience ${ }^{39}$ & Blood sugar-dependent mode of action ${ }^{19,20}$ & $\begin{array}{l}\text { Reduction of insulin-associated weight } \\
\text { gain, by decreasing insulin dose } \mathrm{e}^{25,32}\end{array}$ \\
\hline No maximum dose-effect threshold ${ }^{39}$ & Counter-regulation of hypoglycemia ${ }^{30,31}$ & \\
\hline \multirow[t]{3}{*}{ Beneficial effects on hypertriglyceridemia ${ }^{18}$} & No weight gain 25,32 & \\
\hline & Primarily targets postprandial glycemia ${ }^{8}$ & \\
\hline & Oral administration ${ }^{26}$ & \\
\hline Disadvantages: insulin & Disadvantages: incretins & $\begin{array}{l}\text { Disadvantages: combination } \\
\text { insulin and linagliptin }\end{array}$ \\
\hline Blood sugar-independent mode of action ${ }^{15}$ & Lack of long-term safety evaluations ${ }^{8}$ & Lack of long-term safety evaluations ${ }^{8}$ \\
\hline Mode of administration ${ }^{39}$ & $\begin{array}{l}\text { Decline of insulin-releasing effect with progressive } \\
\text { beta cell failure }{ }^{24}\end{array}$ & \\
\hline \multicolumn{3}{|l|}{ Associated with weight gain ${ }^{32}$} \\
\hline High risk for hypoglycemia ${ }^{29}$ & & \\
\hline
\end{tabular}


A special focus of investigation should be further put on the safety of such treatments in the distinct populations of T2DM. Consequently, the efficacy and safety of add-on linagliptin treatment was also investigated in a population of T2DM patients with severe renal impairment (RI) and a vulnerable population of elderly T2DM patients aged 70 years and over.

\section{Efficacy and safety of linagliptin in combination with insulin in patients with type 2 diabetes and severe renal impairment}

Linagliptin has certain pharmacological properties that differ from the other DPP-4 inhibitors: Excretion happens predominantly via bile and gut, whereas renal excretion is low. The metabolites of the drug do not play a major role in its elimination, as most of the substance is excreted unchanged. ${ }^{43}$ These pharmacological aspects make linagliptin stand out in its class. Other DPP-4 inhibitors, like sitagliptin, vildagliptin, saxagliptin, and alogliptin, are mainly excreted in the urine. Thus, with these drugs, adjustment of the dose according to the patient's estimated glomerular filtration rate (eGFR) is necessary, ${ }^{44}$ which is an important consideration for the use in patients with renal impairment. Previous studies have shown that linagliptin exposure does not vary in patients with normal, mild, moderate, or severe RI. Therefore, linagliptin does not require dose adjustment in patients with declining renal function. ${ }^{45}$ This makes the drug very convenient for patients with T2DM and RI. Renal complications are frequent in T2DM, and approximately 40 percent of patients with T2DM have some degree of renal impairment. ${ }^{46}$ Diabetic nephropathy is the leading cause of end-stage renal disease, eventually requiring chronic dialysis or kidney transplantation. ${ }^{5}$ It therefore is very important to develop optimal treatment strategies for diabetes management in patients with T2DM and RI. Consequently, the efficacy and safety of add-on linagliptin treatment to existing glucose-lowering therapy was investigated in the specific population of T2DM patients with severe renal impairment (chronic kidney disease stage 4/5). ${ }^{1}$ In a Phase 3, multicenter, randomized, doubleblind, placebo controlled, parallel group clinical study, a total of 133 study participants were enrolled. All of the patients matched the inclusion parameters: eGFR $<30 \mathrm{~mL} /$ $\min / 1.73 \mathrm{~m}^{2}$ at screening, $\mathrm{HbA}_{1 \mathrm{c}}>7.0 \%$ and $\leq 10 \%$, and body mass index $(\mathrm{BMI}) \leq 45 \mathrm{~kg} / \mathrm{m}^{2}$. Linagliptin was assessed as add-on therapy to existing background therapy maintained stable during the first 12 weeks of treatment. During the fol- lowing 40-week treatment period, the insulin and/or other antidiabetic background therapy dose could be adjusted according to protocol-specified glucose parameters. The study provided complete and cumulative efficacy and safety data for the 1 year of data collection, with the endpoint of change from baseline in $\mathrm{HbA}_{1 \mathrm{c}}$, after 12 and after 52 weeks of treatment.

The treatment differences for linagliptin versus placebo were $-0.60 \%(95 \% \mathrm{CI}:-0.89$ to -0.31$)(P<0.0001)$ at week 12 and $-0.72 \%(95 \% \mathrm{CI}:-1.03$ to -0.41$)(P<0.0001)$ at week 52. A sustained reduction of $\mathrm{HbA}_{1 \mathrm{c}}$ over the time was achieved with linagliptin treatment, even when dose adjustment in the background therapy was permitted after 12 weeks. The decrease in fasting blood glucose, as adjusted mean change from baseline to week 12 and week 52 respectively, was comparable in both groups - at week 12 , this was $-0.49 \mathrm{mmol} / \mathrm{L}$ for linagliptin versus $-0.39 \mathrm{mmol} / \mathrm{L}$ for placebo, with a treatment difference of -0.10 (95\% CI: -1.35 to 1.16$)(P=0.8802)$; whereas at week 52 , this was $-0.30 \mathrm{mmol} / \mathrm{L}$ for linagliptin versus $-0.38 \mathrm{mmol} / \mathrm{L}$ for placebo, with a treatment difference of 0.07 (95\% CI: -0.82 to 0.97$)(P=0.8698)$. The absolute change in dose of insulin dose up to week 52 was -6.2 IU (SE 4.7) for patients treated with linagliptin and was -0.3 IU (SE 2.1) for patients treated with placebo. Over the 1-year treatment period, body weight decreased in both groups. At week 52, the adjusted mean changes from baseline in body weight were $-1.83 \mathrm{~kg}$ with linagliptin versus $-0.29 \mathrm{~kg}$ with placebo, with a treatment difference of $-1.53 \mathrm{~kg}(95 \% \mathrm{CI}$ : -4.11 to 1.04$)$ $(P=0.2370)$. Renal function parameters, assessed as safety parameters, were comparable between linagliptin and placebo, with no distinct decrease over time in either group (the average eGFR median difference from baseline to the last value on treatment was $-0.8 \mathrm{~mL} / \mathrm{min} / 1.73 \mathrm{~m}^{2}$ for linagliptin and was $-2.2 \mathrm{~mL} / \mathrm{min} / 1.73 \mathrm{~m}^{2}$ for placebo). The reported safety and laboratory results were comparable between linagliptin and placebo, with no distinct safety concerns observed. The incidence of asymptomatic hypoglycemic events were greater in the linagliptin treatment group, which resulted in a higher overall incidence of hypoglycemia in patients treated with linagliptin than with placebo (linagliptin: $63.2 \%$; placebo: $49.2 \%$ ). This was only observed prior to week 12 , when dose adjustment of background therapy was not permitted. There was no difference between the groups regarding severe hypoglycemic events (linagliptin: 4.4\%; placebo: 4.6\%). Linagliptin trough levels measured in patients with severe renal impairment were similar across visits (ranging from 7 to $10 \mathrm{nmol} / \mathrm{L}$ ) and comparable with levels previously seen in patients with normal renal function, and with mild or moderate 
renal impairment. ${ }^{47}$ This study showed that the combination of linagliptin with other glucose-lowering therapies, including insulin, offers an effective and safe treatment option through significant long-term reductions in $\mathrm{HbA}_{1 \mathrm{c}}$, in this population of T2DM patients with severe renal impairment. The findings are very interesting, since appropriate antihyperglycemic therapies for patients with T2DM and renal impairment are rare. Metformin and some sulfonylureas have contraindications or recommended dose adjustments related to renal impairment. ${ }^{48}$ Thiazolidinediones must also be used with caution because of the increased risk of fluid retention and heart failure. ${ }^{49}$ DPP-4 inhibitors have been proven safe and efficacious in patients with T2DM and renal impairment, but accumulation in the plasma may represent a potential risk for unknown adverse events. Saxagliptin, sitagliptin, and vildagliptin are allowed to be prescribed in renal impairment with eGFR $<60 \mathrm{~mL} / \mathrm{min}$ but only when an appropriate dose adjustment is conducted. ${ }^{50,51}$ Linagliptin is the only drug of this class that does not need a dose adjustment in RI. Dose adjustment according to periodic renal function tests always carries the risk of dosing errors, especially when a drug is available in different strengths. Linagliptin is effective and safe in one strength $(5 \mathrm{mg})$, in a once-daily dose This represents a major advantage in the treatment of patients with T2DM and renal impairment. In patients with renal impairment requiring insulin therapy, this advantage is even more important. Renal clearance of insulin is compromised when GFR declines, ${ }^{52}$ predisposing the patient to hypoglycemia. Limited therapeutic options, as well as frequent comorbidities and the risk of hypoglycemia make hyperglycemic management in these patients particularly difficult. In the above described study ${ }^{1}$ it was shown, that linagliptin as add-on therapy to insulin has a favorable safety and tolerability profile in patients with renal impairment. The reported safety and laboratory results were comparable between linagliptin and the placebo, with no distinct safety concerns. However, with sulfonylurea or insulin, a higher incidence of asymptomatic hypoglycemic events was observed in the linagliptin treatment group prior to week 12 , when dose adjustment of the background therapy was not permitted. With dose adjustment after week 12, the reported rates were comparable with those for the placebo. There is already more data concerning the use of other DPP-4 inhibitors as add-on therapy to insulin in patients with renal impairment. A double-blind, randomized, placebo-controlled study with a dose adjustment to $50 \mathrm{mg}$ /day of vildagliptin added to ongoing antidiabetic therapy (mostly insulin) was carried out in patients with T2DM and moderate or severe RI. ${ }^{53}$ While a robust reduction in $\mathrm{HbA}_{1 \mathrm{c}}$ was observed, a slightly higher rate of hypoglycemia was seen in vildagliptin-treated patients with moderate renal impairment. In T2DM with moderate to severe renal failure, the hypoglycemia rates were similar for vildagliptin and placebo, and the risk of severe hypoglycemia was very low and similar to placebo, in both patients with moderate and severe renal failure. ${ }^{53}$ For saxagliptin, one study assessed efficacy and safety in patients with T2DM and renal impairment, with the majority of patients enrolled being treatmed with insulin. ${ }^{51}$ The findings were comparable with those of the other studies, demonstrating a safe and effective profile for saxagliptin in patients with T2DM and renal impairment.

When discussing the application of incretin-based therapy in renal impairment, there is more to consider than the efficacy and safety aspects for blood sugar control. Most interestingly, there may be additional effects on renal function. GLP-1R and DPP-4 are also expressed in the kidney, probably being involved in the regulation of natrium reabsorption. The preclinical data of DPP-4 inhibitors and GLP-1R agonists suggest positive effects on murine and human renal natrium and fluid excretion. ${ }^{54,55}$ Since natriuresis and diuresis are present with DPP-4 inhibition in GLP-1R-deficient mice, it can be assumed that the renal effects of DPP-4 inhibition are in part independent of the GLP-1R. ${ }^{54}$ It is especially interesting to better understand how GLP-1R agonists and DPP-4 inhibitors affect renal reabsorption of fluid and natrium in the diabetic kidney. In a mouse model of diabetic nephropathy, add-on treatment of linagliptin to angiotensin receptor blockade significantly reduced urinary albumin excretion and oxidative stress. ${ }^{55}$ In patients with T2DM and early diabetic nephropathy receiving stable angiotensin-converting enzyme inhibitor/angiotensin II receptor blocker therapy, linagliptin as monotherapy or in combination with one or two oral antihyperglycemic drugs was able to significantly reduce the urinary albumin-to-creatinine ratio compared with placebo. ${ }^{56}$ This data was obtained from a pooled analysis of data from four similarly designed Phase 3 trials. In order to specifically evaluate the albuminlowering potential of linagliptin and to find out whether the albumin-lowering effect is glucose-independent, a randomized trial has recently been initiated (MARLINA [Efficacy, safety \& Modification of Albuminuria in type 2 diabetes subjects with Renal disease with LINAgliptin], NCT01792518). ${ }^{57}$

\section{Efficacy and safety of linagliptin in combination with insulin in elderly patients with type 2 diabetes}

For the treatment of T2DM in patients aged 65 and over, special considerations have to be given. As life expectancy 
has increased and the prevalence of T2DM increases with advancing age, this population is constantly growing. ${ }^{58}$ Pharmacokinetics and pharmacodynamics may be different in elderly patients, thus safety and efficacy have to be analyzed carefully. Elderly patients with T2DM often are burdened with comorbidities, like cardiovascular disease, renal dysfunction, and a higher risk for adverse events, because of drug-drug interactions arising from polypharmacy. ${ }^{59}$ Hypoglycemia is a very common $\mathrm{AE}$ in this population, ${ }^{60}$ and the treatment strategy should focus on safety rather than solely on glycemic targets. Incretin therapy is associated with a low risk of hypoglycemia when added to insulin therapy. Thus, a specific focus on add-on of linagliptin therapy to insulin in the elderly was the subject of the following study. In a Phase 3 randomized, multicenter, double-blind, placebo-controlled, parallel group study, $5 \mathrm{mg}$ linagliptin were administered orally once daily over 24 weeks to T2DM patients aged $\geq 70$ years. $^{2}$ All 241 patients had insufficient glycemic control $\left(\mathrm{HbA}_{1 \mathrm{c}} \geq 7.0 \%\right)$ despite metformin and/or sulfonylurea and/or insulin therapy. With linagliptin treatment, a better reduction of blood glucose was achieved at week 24, as compared with placebo. The adjusted mean change from baseline in $\mathrm{HbA}_{1 \mathrm{c}}$ between linagliptin and the placebo was $-0.64 \%$ (95\% CI: -0.81 to -0.48$)(P<0.0001)$ and was $-1.15 \mathrm{mmol} / \mathrm{L}(95 \% \mathrm{CI}:-1.68$ to -0.62$)(P<0.0001)$ in fasting blood glucose. The difference between the groups was sustained up to 24 weeks, even when dose changes in background therapy were permitted after week 12 . The target treatment outcome of $\mathrm{HbA}_{1 \mathrm{c}}<7.0 \%$ after 24 weeks was achieved significantly more often in patients on linagliptin treatment (linagliptin: 38.9\%; placebo: 8.3\%) (OR 8.32, 95\% CI: 3.32 to 20.84$)(P<0 \cdot 0001)$. The safety assessment did not reveal any major concerns for treatment with linagliptin in the elderly population. The percentage of patients reporting adverse events was the same in both treatment groups. Only a small number of adverse events was considered to be related to the study drug $(21.0 \%$ of patients on linagliptin versus $13.9 \%$ of patients on placebo). Body weight was not influenced by linagliptin treatment. A slightly higher overall incidence of hypoglycemia was observed with linagliptin treatment than with placebo (linagliptin: 24.1\%; placebo: 16.5\%). This difference between the groups was not statistically significant and was attributed to background sulfonylurea treatment. Hypoglycemia was similar between groups in patients not receiving sulfonylureas (linagliptin: $14.9 \%$; placebo: $16.7 \%$ ) and in those receiving metformin alone or insulin. One severe hypoglycemic event was observed in the linagliptin group on background metformin plus sulfonylurea. Sulfonylureas increase circulating insulin in a glucose-independent manner, which is the reason for the known risk of associated hypoglycemia. Several medications will increase circulating concentrations of sulfonylurea by inhibiting renal excretion or reducing the metabolism of the drug. ${ }^{61}$ This is especially important for elderly patients because comorbidities and longstanding disease often require treatment with multiple drugs. Other reasons for hypoglycemia in elderly subjects may be a compromised counter-regulation and hypoglycemia unawareness because of cognitive dysfunction, which is also a consequence of hyopglycemia. ${ }^{62}$ As mentioned, linagliptin did not increase the risk of hypoglycemia relative to placebo when added to basal insulin therapy (with or without metformin and/or pioglitazone). A prespecified pooled analysis included data from this trial in elderly patients ${ }^{2}$ and the trial $^{3}$ discussed above. It showed that linagliptin as add-on therapy to basal insulin in elderly patients (aged $\geq 70$ years) with inadequately controlled T2DM did not increase the risk of hypoglycemia, relative to placebo. ${ }^{63}$ This was confirmed by a post hoc pooled analysis using data from seven randomized, double-blind, placebo-controlled Phase 3 trials. Included were patients aged $\geq 65$ years, treated with linagliptin $5 \mathrm{mg}$ once daily as monotherapy or in addition to common glucoselowering therapies. The treatment was well tolerated, linagliptin improved glycemic control, and the incidence of hypoglycemia was comparable with that of the placebo. ${ }^{64}$ Studies of the other DPP-4 inhibitors, specifically designed for older patients, have only been conducted for monotherapies or in combination with metformin, sulfonylureas, or thiazolidinediones. ${ }^{65}$ No other data concerning the add-on of DPP-4 inhibitors to insulin in elderly patients with T2DM are available so far. Table 2 shows the efficacy data from the clinical trials of linagliptin as add-on to insulin and other antidiabetic therapies.

\section{Cardiovascular risk}

Patients with diabetes have an increased risk of cardiovascular (CV) disease. ${ }^{66}$ The development of CV complications is triggered by frequent conditions associated with T2DM, like chronic elevated blood glucose, obesity, hypertension, and dyslipidemia. Thus, one major aim of glycemic control is decreasing the risk for $\mathrm{CV}$ disease. The lowering of blood glucose, which is known to reduce the incidence of microvascular disease, does not necessarily reflect reduced macrovascular complications. ${ }^{4}$ This finding put the common treatment strategies of tight glycemic control into question. Results of three large randomized trials looking at intensive glycemic control raised the awareness of hypoglycemia as a risk factor for cardiovascular events. Two large studies, ADVANCE (Action in Diabetes and Vascular disease: preterAx and diamicroN MR Controlled Evaluation) ${ }^{67}$ and VADT (Vet- 


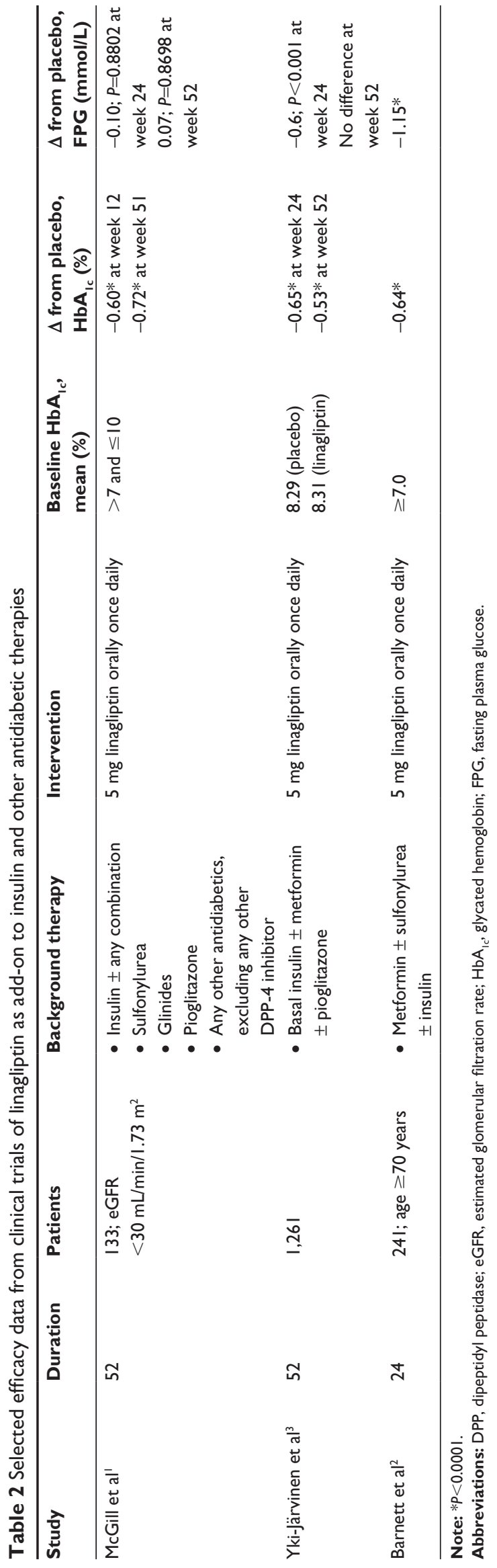

erans Affairs Diabetes Trial), ${ }^{68}$ failed to show any benefits regarding reduction in the primary combined cardiovascular end points, and the third study ACCORD (Action to Control Cardiovascular Risk in Diabetes ${ }^{69}$ showed an increased allcause mortality, mainly driven by CV mortality. However, the meta-analysis of $\mathrm{CV}$ outcome in these trials suggested that reduction of blood glucose may be associated with relative risk reduction in nonfatal myocardial infarction but without benefits on stroke or all-cause mortality. Since then, larger clinical trials looking specifically at the association between hypoglycemia and $\mathrm{CV}$ events have been lacking, but currently there is no evidence for this causality. ${ }^{70}$ However, besides the existing uncertainty regarding the $\mathrm{CV}$ safety of intense glucose control, there have been additional concerns about the CV safety of certain OADs, like rosiglitazone ${ }^{71}$ and the sulfonylureas. ${ }^{72,73}$ As a consequence, in 2008, the FDA implemented guidelines for establishing the CV safety of new antidiabetic drugs in large, long-term CV safety studies or in meta-analyses of pooled data from Phase 2 and 3 trials. ${ }^{74}$ Consequently, since then all new antidiabetic agents under investigation have been carefully reviewed in systematic analyses, with the main readouts, defined by the FDA, being $\mathrm{CV}$ death, myocardial infarction, and stroke. For treatment with DPP-4 inhibitors, meta-analyses so far have not found an association with increased CV risk. Meta-analysis of linagliptin Phase 3 studies has showed no increased cardiovascular risk with linagliptin and suggests a neutral or beneficial effect in T2DM. ${ }^{75}$ In a pooled analysis for the specific population of T2DM patients with increased renal and cardiovascular risk, linagliptin was well tolerated and achieved a significant lowering of blood glucose. ${ }^{76}$ In patients with T2DM inadequately controlled on metformin, linagliptin was associated with significantly fewer cardiovascular events compared with sulfonylurea treatment. ${ }^{77}$ Until now, there has been quite a remarkable amount of data addressing the question of CV safety in DPP-4 inhibition, ${ }^{78-80}$ but definitive data from ongoing $\mathrm{CV}$ morbidity and mortality studies have yet to come. To evaluate the long-term CV outcomes of linagliptin treatment in humans, there is a large $(n=6,000)$, doubleblind, multicenter study currently going on, with a planned study end for 2018. Patients included in the CAROLINA (CARdiovascular Outcome study of LINAgliptin versus glimepiride in early type 2 diabetes) trial (NCT01243424) have T2DM and a high cardiovascular risk. ${ }^{81}$ It is the only ongoing $\mathrm{CV}$ outcome study with an active comparator. For several other DPP-4 inhibitors ${ }^{82,83}$ and GLP-1R agonists, ${ }^{84,85}$ ongoing placebo-controlled studies are evaluating CV safety in T2DM. In September 2013, the results of the Saxagliptin 
Assessment of Vascular Outcomes Recorded in Patients with Diabetes Mellitus (SAVOR-TIMI-53) (6) $^{86}$ clinical trial were presented at the meeting of the European Society of Cardiology. It was shown that saxagliptin neither reduced nor increased the risk of the primary composite endpoint of $\mathrm{CV}$ death, myocardial infarction, or ischemic stroke, when added to a patient's current standard of care. However, an unexpected higher incidence of hospitalization for heart failure was observed. This once again confirms the importance of examining cardiovascular endpoints for substances used in diabetes treatment. Still, there are great expectations in the upcoming results of the other CV safety studies since preclinical research and post hoc analyses of clinical trials have come up with interesting findings suggesting a positive cardiovascular risk profile of DPP-4 inhibition. Linagliptin may exert beneficial CV effects independent of improvement of glycemic control. It reduces oxidative stress, ${ }^{55}$ improves the outcome after myocardial ischemia, ${ }^{87}$ and may be beneficial in the setting of nondiabetic uremic cardiomyopathy ${ }^{88}$ The current outcome study CAROLINA will show whether these preclinical data can be translated into clinical benefit.

\section{Patient-centered therapy}

The arising uncertainty about possible adverse effects of an intense glucose control has led to a debate about the degree of glycemic control required to decrease diabetes complications. It has also opened the way for a discussion about the need of a more individualized therapy for T2DM. Given the heterogeneity in clinical presentation, features, and pathogenesis of T2DM, it is only reasonable to avoid treating patients similarly, independent of underlying differences in phenotype and genotype. The recent advent of new treatment options, already approved or in clinical development, can contribute to a substantial change in the management of T2DM. Patient-centered care puts the medical treatment within the context of the patient's expectations, needs, and values and involves him/her in medical decisions. Patient and clinician work as a team to achieve glycemic control and avoid hypoglycemia. ${ }^{89}$ The most important step is defining an individual $\mathrm{HbA}_{1 \mathrm{c}}$, which includes taking a decision between an intense or a conservative regimen. Background considerations are safety and tolerability, side effects, and the patient's comorbidities, like renal impairment. Adherence will be influenced by the preferred route of administration, dosing frequency, the desire for weight loss, and eventually by costs. The individualization of the therapy, together with respect for lifestyle choices and encouragement to follow the medication strategy may enhance compliance and lead to a higher quality of life. ${ }^{15}$ Once insulin substitution becomes inevitable, the most appropriate regimen must be selected. This involves a well-considered decision between the different insulin preparations, treatment approaches, and combination options. Combining insulin with an incretinbased therapy offers a safe and effective treatment option. Psychological stress linked to the initiation of insulin therapy, especially concerns about weight gain and hypoglycemia, can be alleviated with combination therapy. This aspect is rather important since diabetes can mean a great compromise to quality of life..$^{90}$ By combining linagliptin with insulin, a dose increase because of declining beta cell function may be avoided. Linagliptin has the advantage of a convenient route of administration and a once-daily, orally taken dose. Gastrointestinal symptoms, transiently associated with oral GLP-1R-agonist therapy, ${ }^{91}$ rarely occur with linagliptin $5 \mathrm{mg}$ once daily, and other adverse events are generally mild or moderate in intensity. Adverse events are comparable with those observed in other currently available DPP-4 inhibitors and the most frequently reported are infections and infestations. Pooled data from the international linagliptin clinical trial program show that the overall incidence of adverse events and rates of treatment discontinuation are similar for patients receiving linagliptin as for those receiving placebo. ${ }^{37}$ Due to its efficacy and safety profile and the abovementioned advantages, linagliptin is well applicable in the context of patient-centered therapy for T2DM, either as monotherapy or in combination with insulin.

\section{Hypoglycemia}

In studies where linagliptin treatment had a higher incidence of hypoglycemia, this was almost exclusively attributable to the combination with sulfonylurea. ${ }^{37}$ As add-on therapy to insulin, linagliptin has the same rates of hypoglycemia as placebo, when not combined with sulfonylurea use. ${ }^{92,93}$ Therapy with sulfonylureas carries a known risk for hypoglycemia. ${ }^{35}$ Accordingly, for the coadministration of sulfonylureas with other glucose-lowering agents, the risk for hypoglycemia is higher. ${ }^{79,94,95}$ The incidence of hypoglycemic events in patients receiving linagliptin without concomitant sulfonylurea is very low, even in vulnerable patients, such as the elderly or those with renal impairment. ${ }^{37}$ When DPP-4 inhibitors are added to sulfonylurea background therapy, a lower dose of sulfonylurea has been recommended, in order to avoid hypoglycemic events. ${ }^{35,96,97}$ In a long-term study in patients with T2DM inadequately controlled on metformin, linagliptin was noninferior to the sulfonylurea glimepiride in lowering $\mathrm{HbA}_{1 \mathrm{c}}$ but was associated with significantly less hypoglycemia. ${ }^{77}$ In patients 


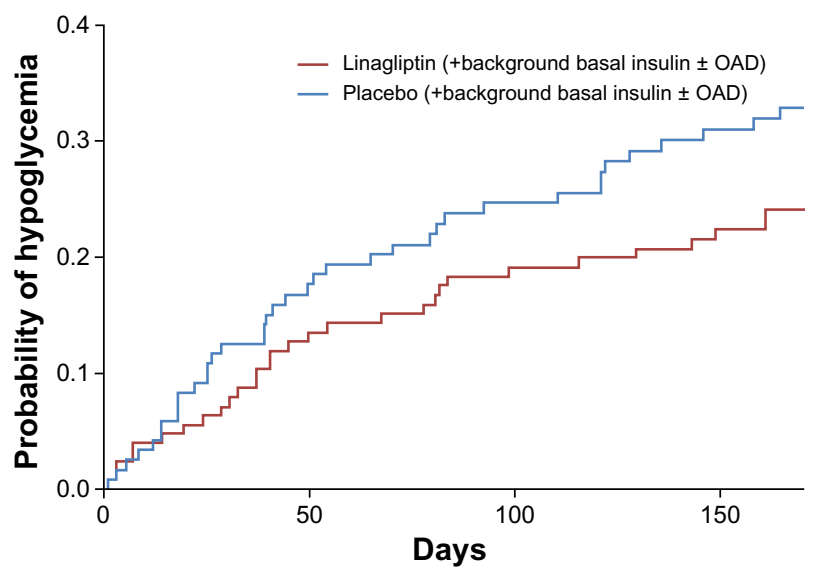

Figure I Risk of overall hypoglycemia modified from Inzucchi et al. ${ }^{100}$ Abbreviation: OAD, oral antidiabetic drug.

with T2DM and severe renal impairment, the observed incidence of asymptomatic hypoglycemic events was higher with linagliptin than with placebo. ${ }^{92}$ This was only the case when a dose adjustment of background therapy of sulfonylurea or insulin was not permitted. When a DPP-4 inhibitor is added to insulin, the dose of insulin should be monitored carefully. With sitagliptin added to ongoing insulin therapy, a higher proportion of patients experienced symptomatic hypoglycemia compared with placebo. ${ }^{41}$ In contrast, the addition of vildagliptin to insulin was associated with a reduced incidence of hypoglycemia relative to placebo. ${ }^{40}$ An explanation is the considerably high underlying incidence of overall hypoglycemia because of a high insulin dose and the multiple daily injections of shortacting insulin in the vildagliptin study. A following study with vildagliptin and predominantly basal insulin in a lower dose showed a smaller incidence of hypoglycemia that was comparable with that of placebo. ${ }^{98}$ For alogliptin as add-on to insulin, a study showed the incidence of hypoglycemia was comparable with that of placebo. ${ }^{99}$ Potential differences in the definition of hypoglycemic events make a comparison between different studies with various DPP-4 inhibitors complicated and may also explain the differences in hypoglycemia rates seen versus placebo between the studies. When comparing study results, one should be aware of the different background insulin therapies as well as the populations and inclusion criteria. However, the overall finding of studies with DPP-4 inhibitors has been a clinically meaningful decrease in $\mathrm{HbA}_{1 \mathrm{c}}$ without increased hypoglycemia. In an exploratory analysis from two Phase 3 studies in elderly patients with long-standing T2DM treated with linagliptin and basal insulin therapy, hypoglycemia risk was explored. ${ }^{100}$ The overall and confirmed hypoglycemia risk was lower with linagliptin versus placebo, despite a significantly reduced $\mathrm{HbA}_{1 \mathrm{c}}$ and no relevant on-trial insulin dose reductions (Figure 1). Interestingly, there is a possible mechanistic explanation for a protection against hypoglycemia by DPP-4 inhibition. It is suggested that DPP-4 inhibition can cause a glucagondependent counter-regulation of hypoglycemia by restored pancreatic alpha cell function (Figure 2). The first mechanistic study directing this question was conducted by Ahrén et al in

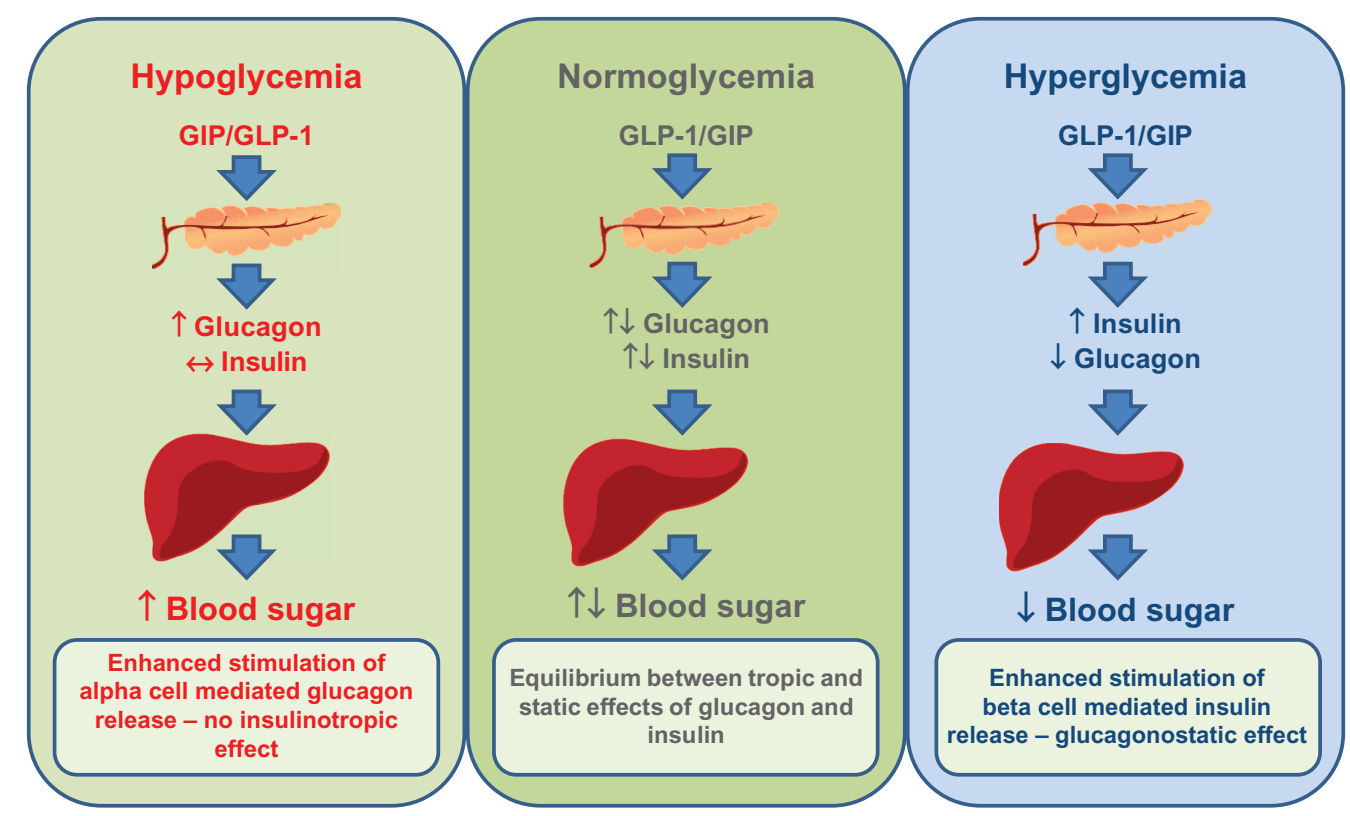

Figure 2 Mode of action of incretins according to glycemic state.

Notes: DPP-4 inhibition leads to an extension of physiological increases in GLP-I and GIP, which also affects the fasting plasma levels of these incretins. However, there is accumulating evidence that GLP-I and GIP have different modes of action according to the glycemic state.

Abbreviations: DPP, dipeptidyl peptidase; GIP, glucose-dependent insulinotropic polypeptide; GLP, glucagon-like peptide. 
$2009 .{ }^{101}$ The glucagon response to hypoglycemia was examined in patients with T2DM by using stepped hypoglycemic clamps. Intervention with vildagliptin resulted in a suppression of glucagon secretion following a meal test. Interestingly, vildagliptin treatment also had stimulatory effects on glucagon secretion during hypoglycemia. The authors assumed there was an improved ability of alpha cells to sense and respond to changes in plasma glucose levels - this would lead to a GLP-1mediated decrease in glucagon secretion during hyperglycemia, and a GIP-mediated stimulation of glucagon secretion during hypoglycemia. Additionally, the glucagonostatic and insulinotropic actions of GLP-1 do not occur under hypoglycemic conditions. ${ }^{102}$ As a matter of fact, Christensen et $\mathrm{al}^{30}$ showed that in healthy humans, GIP has insulinotropic effects during hyperglycemia, while it has no effects on glucagon secretion. During fasting and hypoglycemic conditions GIP increased glucagon levels but had little or no effect on insulin secretion. This physiological bifunctional action of the hormone could, in part, explain the smaller incidence of hypoglycemia observed with DPP-4 inhibitor treatment. Since then, no further studies have addressed and evaluated the hypothesis of improved alpha cell function. Consequently, more studies are warranted to examine the effect of linagliptin on alpha cell function and to bring evidence of how linagliptin treatment relates to counterregulatory responses to hypoglycemia.

\section{Conclusion}

Three clinical trials looking at linagliptin in combination with insulin have shown that this combination is suited to improve glycemic control without additional risk for hypoglycemia, in different populations of T2DM. The overall safety profile was similar to that of placebo. No dose adjustment was necessary in elderly patients or in those with impaired renal function. The studies show that the use of linagliptin in combination with insulin could be an attractive therapeutic option for patients with T2DM. An individualized glycemic control can be achieved, while minimalizing the risk for hypoglycemia. However, additional clinical trials are warranted in order to examine the long term efficacy and safety of linagliptin as add-on therapy to insulin.

\section{Disclosure}

The authors report no conflicts of interest in this work.

\section{References}

1. McGill JB, Sloan L, Newman J, et al. Long-term efficacy and safety of linagliptin in patients with type 2 diabetes and severe renal impairment: a 1-year, randomized, double-blind, placebo-controlled study. Diabetes Care. 2013;36(2):237-244.
2. Barnett AH, Huisman H, Jones R, von Eynatten M, Patel S, Woerle HJ Linagliptin for patients aged 70 years or older with type 2 diabetes inadequately controlled with common antidiabetes treatments: a randomised, double-blind, placebo-controlled trial. Lancet. Epub 2013 Aug 13.

3. Yki-Jarvinen H, Rosenstock J, Duran-Garcia S, et al. Effects of Adding Linagliptin to Basal Insulin Regimen for Inadequately Controlled Type 2 Diabetes: A $\geq 52$-week randomized, double-blind study. Diabetes Care. 2013. Epub 2013 Sep 23.

4. Sarwar N, Gao P, Seshasai SR, et al; Emerging Risk Factors Collaboration. Diabetes mellitus, fasting blood glucose concentration, and risk of vascular disease: a collaborative meta-analysis of 102 prospective studies. Lancet. 2010;375(9733):2215-2222.

5. Centers for Disease Control and Prevention. National Diabetes Fact Sheet: National Estimates and General Information on Diabetes and Prediabetes in the United States, 2011. Atlanta, GA: US Department of Health and Human Services, Centers for Disease Control and Prevention; 2011. Available from: http://www.cdc.gov/diabetes/pubs/pdf/ ndfs_2011.pdf. Accessed July 11, 2013.

6. American Diabetes Association. Standards of medical care in diabetes 2013. Diabetes Care. 2013;36 Suppl 1:S11-S66.

7. Baggio LL, Drucker DJ. Biology of incretins: GLP-1 and GIP. Gastroenterology. 2007;132(6):2131-2157.

8. Drucker DJ, Nauck MA. The incretin system: glucagon-like peptide-1 receptor agonists and dipeptidyl peptidase-4 inhibitors in type 2 diabetes. Lancet. 2006;368(9548):1696-1705.

9. Mentlein R, Gallwitz B, Schmidt WE. Dipeptidyl-peptidase IV hydrolyses gastric inhibitory polypeptide, glucagon-like peptide-1(7-36)amide, peptide histidine methionine and is responsible for their degradation in human serum. Eur J Biochem. 1993;214(3):829-835.

10. Rodbard HW, Jellinger PS, Davidson JA, et al. Statement by an American Association of Clinical Endocrinologists/American College of Endocrinology consensus panel on type 2 diabetes mellitus: an algorithm for glycemic control. Endocr Pract. 2009;15(6):540-559.

11. National Institute for Health and Clinical Excellence. Type 2 Diabetes: Newer Agents for Blood Glucose Control in Type 2 Diabetes. London: National Institute for Health and Clinical Excellence; 2009. Available from: http://www.nice.org.uk/nicemedia/pdf/CG87ShortGuideline.pdf. Accessed May 29, 2013

12. Kahn SE, Haffner SM, Heise MA, et al; ADOPT Study Group. Glycemic durability of rosiglitazone, metformin, or glyburide monotherapy. N Engl J Med. 2006;355(23):2427-2443.

13. Nichols GA, Alexander CM, Girman CJ, Kamal-Bahl SJ, Brown JB. Treatment escalation and rise in $\mathrm{HbA}_{1 \mathrm{c}}$ following successful initial metformin therapy. Diabetes Care. 2006;29(3):504-509.

14. Brown JB, Conner C, Nichols GA. Secondary failure of metformin monotherapy in clinical practice. Diabetes Care. 2010;33(3):501-506.

15. Inzucchi SE, Bergenstal RM, Buse JB, et al; American Diabetes Association (ADA); European Association for the Study of Diabetes (EASD). Management of hyperglycemia in type 2 diabetes: a patient-centered approach: position statement of the American Diabetes Association (ADA) and the European Association for the Study of Diabetes (EASD). Diabetes Care. 2012;35(6):1364-1379.

16. Li Y, Xu W, Liao Z, et al. Induction of long-term glycemic control in newly diagnosed type 2 diabetic patients is associated with improvement of beta-cell function. Diabetes Care. 2004;27(11):2597-2602.

17. Xu L, Man CD, Charbonnel B, et al. Effect of sitagliptin, a dipeptidyl peptidase-4 inhibitor, on beta-cell function in patients with type 2 diabetes: a model-based approach. Diabetes Obes Metab. 2008;10(12): $1212-1220$.

18. Nathan DM, Roussell A, Godine JE. Glyburide or insulin for metabolic control in non-insulin-dependent diabetes mellitus. A randomized, double-blind study. Ann Intern Med. 1988;108(3):334-340.

19. Ahrén B, Holst JJ, Mari A. Characterization of GLP-1 effects on beta-cell function after meal ingestion in humans. Diabetes Care. 2003;26(10):2860-2864.

20. Holst JJ, Christensen M, Lund A, et al. Regulation of glucagon secretion by incretins. Diabetes Obes Metab. 2011;13 Suppl 1:89-94. 
21. Jelsing J, Vrang N, van Witteloostuijn SB, Mark M, Klein T. The DPP4 inhibitor linagliptin delays the onset of diabetes and preserves $\beta$-cell mass in non-obese diabetic mice. J Endocrinol. 2012;214(3):381-387.

22. Akarte AS, Srinivasan BP, Gandhi S. A novel long acting DPP-IV inhibitor PKF-275-055 stimulates $\beta$-cell proliferation resulting in improved glucose homeostasis in diabetic rats. Biochem Pharmacol. 2012;83(2):241-252.

23. Brazg R, Xu L, Dalla Man C, Cobelli C, Thomas K, Stein PP. Effect of adding sitagliptin, a dipeptidyl peptidase- 4 inhibitor, to metformin on 24-h glycaemic control and beta-cell function in patients with type 2 diabetes. Diabetes Obes Metab. 2007;9(2):186-193.

24. Bosi E. Time for testing incretin therapies in early type 1 diabetes? J Clin Endocrinol Metab. 2010;95(6):2607-2609.

25. Buse JB, Bergenstal RM, Glass LC, et al. Use of twice-daily exenatide in Basal insulin-treated patients with type 2 diabetes: a randomized, controlled trial. Ann Intern Med. 2011;154(2):103-112.

26. Campbell RK. Clarifying the role of incretin-based therapies in the treatment of type 2 diabetes mellitus. Clin Ther. 2011;33(5):511-527.

27. Monami M, Dicembrini I, Martelli D, Mannucci E. Safety of dipeptidyl peptidase-4 inhibitors: a meta-analysis of randomized clinical trials. Curr Med Res Opin. 2011;27 Suppl 3:57-64.

28. diabetes.org [homepage on the Internet]. ADA/EASD/IDF Statement concerning the use of incretin therapy and pancreatic disease [ADA news release]. American Diabetes Association; 2013 [updated June 28, 2013; cited July 10, 2013]. Available from: http://www.diabetes.org/formedia/2013/recommendations-for.html. Accessed September 25, 2013.

29. Cryer PE. Hypoglycaemia: the limiting factor in the glycaemic management of Type I and Type II diabetes. Diabetologia. 2002;45(7): 937-948.

30. Christensen M, Vedtofte L, Holst JJ, Vilsbøll T, Knop FK. Glucosedependent insulinotropic polypeptide: a bifunctional glucose-dependent regulator of glucagon and insulin secretion in humans. Diabetes. 2011;60(12):3103-3109.

31. Ahrén B, Foley JE, Bosi E. Clinical evidence and mechanistic basis for vildagliptin's action when added to metformin. Diabetes Obes Metab. 2011;13(3):193-203.

32. Hermansen K, Mortensen LS. Bodyweight changes associated with antihyperglycaemic agents in type 2 diabetes mellitus. Drug Saf. 2007;30(12):1127-1142.

33. Scheen AJ. Pharmacokinetics of dipeptidylpeptidase-4 inhibitors. Diabetes Obes Metab. 2010;12(8):648-658.

34. Thomas L, Eckhardt M, Langkopf E, Tadayyon M, Himmelsbach F, Mark M. (R)-8-(3-amino-piperidin-1-yl)-7-but-2-ynyl-3-methyl-1-(4methyl-quinazolin-2-ylmethyl)-3,7-dihydro-purine-2,6-dione (BI 1356), a novel xanthine-based dipeptidyl peptidase 4 inhibitor, has a superior potency and longer duration of action compared with other dipeptidyl peptidase-4 inhibitors. J Pharmacol Exp Ther. 2008;325(1):175-182.

35. Tradjenta ${ }^{\circledR}$ (linagliptin) tablets [package insert]. Ridgefield, CT: Boehringer Ingelheim Pharmaceuticals, Inc; 2011.

36. fda.gov [homepage on the internet]. Tradjenta (linagliptin) Prescribing Information September 2012; Available from: http://www.accessdata. fda.gov/drugsatfda_docs/label/2012/201280s005lbl.pdf. Accessed October 9, 2013.

37. Schernthaner G, Barnett AH, Emser A, et al. Safety and tolerability of linagliptin: a pooled analysis of data from randomized controlled trials in 3572 patients with type 2 diabetes mellitus. Diabetes Obes Metab. 2012;14(5):470-478.

38. Deacon CF, Holst JJ. Linagliptin, a xanthine-based dipeptidyl peptidase-4 inhibitor with an unusual profile for the treatment of type 2 diabetes. Expert Opin Investig Drugs. 2010;19(1):133-140.

39. Nathan DM, Buse JB, Davidson MB, et al; American Diabetes Association; European Association for Study of Diabetes. Medical management of hyperglycemia in type 2 diabetes: a consensus algorithm for the initiation and adjustment of therapy: a consensus statement of the American Diabetes Association and the European Association for the Study of Diabetes. Diabetes Care. 2009;32(1):193-203.
40. Fonseca V, Schweizer A, Albrecht D, Baron MA, Chang I, Dejager S. Addition of vildagliptin to insulin improves glycaemic control in type 2 diabetes. Diabetologia. 2007;50(6):1148-1155.

41. Vilsbøll T, Rosenstock J, Yki-Järvinen H, et al. Efficacy and safety of sitagliptin when added to insulin therapy in patients with type 2 diabetes. Diabetes Obes Metab. 2010;12(2):167-177.

42. Barnett AH, Charbonnel B, Donovan M, Fleming D, Chen R. Effect of saxagliptin as add-on therapy in patients with poorly controlled type 2 diabetes on insulin alone or insulin combined with metformin. Curr Med Res Opin. 2012;28(4):513-523.

43. Blech S, Ludwig-Schwellinger E, Gräfe-Mody EU, Withopf B, Wagner K. The metabolism and disposition of the oral dipeptidyl peptidase-4 inhibitor, linagliptin, in humans. Drug Metab Dispos. 2010;38(4):667-678.

44. Deacon CF. Dipeptidyl peptidase-4 inhibitors in the treatment of type 2 diabetes: a comparative review. Diabetes Obes Metab. 2011;13(1): $7-18$.

45. Graefe-Mody U, Friedrich C, Port A, et al. Effect of renal impairment on the pharmacokinetics of the dipeptidyl peptidase-4 inhibitor linagliptin(*). Diabetes Obes Metab. 2011;13(10):939-946.

46. Plantinga LC, Crews DC, Coresh J, et al; CDC CKD Surveillance Team. Prevalence of chronic kidney disease in US adults with undiagnosed diabetes or prediabetes. Clin J Am Soc Nephrol. 2010;5(4):673-682.

47. Friedrich C, Emser A, Woerle H-J, Graefe-Mody U. Renal Impairment Has No Clinically Relevant Effect on the Long-Term Exposure of Linagliptin in Patients With Type 2 Diabetes. Am J Ther. 2013. Epub $2013 \mathrm{Feb} 13$

48. Russo E, Penno G, Del Prato S. Managing diabetic patients with moderate or severe renal impairment using DPP-4 inhibitors: focus on vildagliptin. Diabetes Metab Syndr Obes. 2013;6:161-170.

49. Chapelsky MC, Thompson-Culkin K, Miller AK, Sack M, Blum R, Freed MI. Pharmacokinetics of rosiglitazone in patients with varying degrees of renal insufficiency. J Clin Pharmacol. 2003;43(3):252-259.

50. Chan JC, Scott R, Arjona Ferreira JC, et al. Safety and efficacy of sitagliptin in patients with type 2 diabetes and chronic renal insufficiency. Diabetes Obes Metab. 2008;10(7):545-555.

51. Nowicki M, Rychlik I, Haller H, et al. Long-term treatment with the dipeptidyl peptidase-4 inhibitor saxagliptin in patients with type 2 diabetes mellitus and renal impairment: a randomised controlled 52-week efficacy and safety study. Int J Clin Pract. 2011;65(12):1230-1239.

52. Mak RH. Impact of end-stage renal disease and dialysis on glycemic control. Semin Dial. 2000;13(1):4-8.

53. Lukashevich V, Schweizer A, Shao Q, Groop PH, Kothny W. Safety and efficacy of vildagliptin versus placebo in patients with type 2 diabetes and moderate or severe renal impairment: a prospective 24-week randomized placebo-controlled trial. Diabetes Obes Metab. 2011;13(10):947-954.

54. Rieg T, Gerasimova M, Murray F, et al. Natriuretic effect by exendin-4, but not the DPP-4 inhibitor alogliptin, is mediated via the GLP-1 receptor and preserved in obese type 2 diabetic mice. Am J Physiol Renal Physiol. 2012;303(7):F963-F971.

55. Alter ML, Ott IM, von Websky K, et al. DPP-4 inhibition on top of angiotensin receptor blockade offers a new therapeutic approach for diabetic nephropathy. Kidney Blood Press Res. 2012;36(1):119-130.

56. Groop PH, Cooper M, Perkovic V, et al. Effects of the DPP-4 inhibitor linagliptin on albuminuria in patients with type 2 diabetes and diabetic nephropathy. Abstract and poster presented at the 72nd Scientific Sessions of the American Diabetes Association; June 8-12; 2012; Philadelphia, PA.

57. Boehringer Ingelheim Pharmaceutic. MARLINA: efficacy, safety and modification of albuminuria in type 2 diabetes subjects with renal disease with linagliptin. Available from: http://www.clinicaltrials.gov/ ct2/show/NCT01792518. NLM identifier: NCT01792518. Accessed May 29, 2013. 
58. Fagot-Campagna A, Bourdel-Marchasson I, Simon D. Burden of diabetes in an aging population: prevalence, incidence, mortality, characteristics and quality of care. Diabetes Metab. 2005;31 Spec No 2: S535-S552.

59. Booth GL, Kapral MK, Fung K, Tu JV. Relation between age and cardiovascular disease in men and women with diabetes compared with non-diabetic people: a population-based retrospective cohort study. Lancet. 2006;368(9529):29-36.

60. Matyka K, Evans M, Lomas J, Cranston I, Macdonald I, Amiel SA. Altered hierarchy of protective responses against severe hypoglycemia in normal aging in healthy men. Diabetes Care. 1997;20(2): 135-141.

61. Ahrén B. Avoiding hypoglycemia: a key to success for glucoselowering therapy in type 2 diabetes. Vasc Health Risk Manag. 2013;9: 155-163.

62. Bauduceau B, Doucet J, Bordier L, Garcia C, Dupuy O, Mayaudon H. Hypoglycaemia and dementia in diabetic patients. Diabetes Metab. 2010;36 Suppl 3:S106-S111.

63. Woehrle HJ, Neubacher D, Patel S, von Eynatten M. Safety and efficacy of linagliptin plus basal insulin combination therapy in a vulnerable population of elderly patients (age $\geq 70$ years) with type 2 diabetes. Poster presented at the 48th Annual Meeting of the European Association for the Study of Diabetes; October 1-5; 2012; Berlin, Germany.

64. Patel S, Schernthaner G, BarnettAH, EmserA, von Eynatten M, Woerle HJ. Safety and efficacy of linagliptin in elderly patients with type 2 diabetes: evidence from 1331 individuals aged $\geq 65$ years [abstract]. Diabetologia. 2012;55(Suppl 1):S351.

65. Paolisso G, Monami M, Marfella R, Rizzo MR, Mannucci E. Dipeptidyl peptidase-4 inhibitors in the elderly: more benefits or risks? Adv Ther 2012;29(3):218-233.

66. Gore MO, McGuire DK. The 10-year post-trial follow-up of the United Kingdom Prospective Diabetes Study (UKPDS): cardiovascular observations in context. Diab Vasc Dis Res. 2009;6(1):53-55.

67. Patel A, Chalmers J, Poulter N. ADVANCE: action in diabetes and vascular disease. J Hum Hypertens. 2005; 19 Supp1 1:S27-S32.

68. Duckworth W, Abraira C, Moritz T, et al; VADT Investigators. Glucose control and vascular complications in veterans with type 2 diabetes. N Engl J Med. 2009;360(2):129-139.

69. Action to Control Cardiovascular Risk in Diabetes Study Group; Gerstein HC, Miller ME, Byington RP, et al. Effects of intensive glucose lowering in type 2 diabetes. N Engl J Med. 2008;358(24):2545-2559.

70. Desouza CV, Bolli GB, Fonseca V. Hypoglycemia, diabetes, and cardiovascular events. Diabetes Care. 2010;33(6):1389-1394.

71. Nissen SE, Wolski K. Effect of rosiglitazone on the risk of myocardial infarction and death from cardiovascular causes. $N$ Engl J Med. 2007;356(24):2457-2471.

72. Jørgensen CH, Gislason GH, Andersson C, et al. Effects of oral glucose-lowering drugs on long term outcomes in patients with diabetes mellitus following myocardial infarction not treated with emergent percutaneous coronary intervention - a retrospective nationwide cohort study. Cardiovasc Diabetol. 2010;9:54.

73. Simpson SH, Majumdar SR, Tsuyuki RT, Eurich DT, Johnson JA. Dose-response relation between sulfonylurea drugs and mortality in type 2 diabetes mellitus: a population-based cohort study. CMAJ. 2006;174(2):169-174.

74. US Department of Health and Human Services, Food and Drug Administration, Center for Drug Evaluation and Research (CDER). Guidance for Industry: Diabetes Mellitus - Evaluating Cardiovascular Risk in New Antidiabetic Therapies to Treat Type 2 Diabetes. Silver Spring, MD: US Department of Health and Human Services; 2008. Available from: http:// www.fda.gov/downloads/Drugs/GuidanceComplianceRegulatoryInfor mation/Guidances/ucm071627.pdf. Accessed September 25, 2013.

75. Johansen OE, Neubacher D, von Eynatten M, Patel S, Woerle HJ. Cardiovascular safety with linagliptin in patients with type 2 diabetes mellitus: a pre-specified, prospective, and adjudicated meta-analysis of a phase 3 programme. Cardiovasc Diabetol. 2012;11:3
76. von Eynatten M, Gong Y, Emser A, Woerle HJ. Efficacy and safety of linagliptin in type 2 diabetes subjects at high risk for renal and cardiovascular disease: a pooled analysis of six phase III clinical trials. Cardiovasc Diabetol. 2013;12:60.

77. Gallwitz B, Rosenstock J, Rauch T, et al. 2-year efficacy and safety of linagliptin compared with glimepiride in patients with type 2 diabetes inadequately controlled on metformin: a randomised, double-blind, non-inferiority trial. Lancet. 2012;380(9840): 475-483.

78. Frederich R, Alexander JH, Fiedorek FT, et al. A systematic assessment of cardiovascular outcomes in the saxagliptin drug development program for type 2 diabetes. Postgrad Med. 2010;122(3): 16-27.

79. Williams-Herman D, Engel SS, Round E, et al. Safety and tolerability of sitagliptin in clinical studies: a pooled analysis of data from 10,246 patients with type 2 diabetes. BMC Endocr Disord. 2010;10:7.

80. Schweizer A, Dejager S, Foley JE, Couturier A, Ligueros-Saylan M, Kothny W. Assessing the cardio-cerebrovascular safety of vildagliptin: meta-analysis of adjudicated events from a large Phase III type 2 diabetes population. Diabetes Obes Metab. 2010;12(6): 485-494.

81. Boehringer Ingelheim Pharmaceuticals. CAROLINA: cardiovascular outcome study of linagliptin versus glimepiride in patients with type 2 diabetes. Available from: http://www.clinicaltrials.gov/ct2/ show/NCT01243424?term=NCT01243424\&rank=1. NLM identifier: NCT01243424. Accessed May 29, 2013.

82. Takeda Global Research and Development Center, Inc. Cardiovascular outcomes study of alogliptin in subjects with type 2 diabetes and acute coronary syndrome (EXAMINE). Available from: http://clinicaltrials. gov/ct2/show/NCT00968708?term=NCT00968708\&rank=1. NLM identifier: NCT00968708. Accessed May 29, 2013.

83. Cobble ME, Frederich R. Saxagliptin for the treatment of type 2 diabetes mellitus: assessing cardiovascular data. Cardiovasc Diabetol. 2012;11:6

84. Amylin Pharmaceuticals, LLC. Exenatide study of cardiovascular event lowering trial (EXSCEL): a trial to evaluate cardiovascular outcomes after treatment with exenatide once weekly in patients with type 2 diabetes mellitus. Available from: http://www.clinicaltrials.gov/ct2/ show/NCT01144338?term=ExenatideStudyofCardiovascularEvent LoweringTrial(EXSCEL)\&rank=1. NLM identifier: NCT01144338. Accessed May 29, 2013.

85. Novo Nordisk. Liraglutide effect and action in diabetes: evaluation of cardiovascular outcome results - a long term evaluation (LEADER ${ }^{\circledR}$ ). Available from: http://www.clinicaltrials.gov/ct2/ show/NCT01 179048?term=LiraglutideEffectandActioninDiabet s(LEADER)\&rank=1. NLM identifier: NCT01179048. Accessed May 29, 2013.

86. Bhatt DL; SAVOR TIMI 53 Steering Committee and Investigators. Saxagliptin assessment of vascular outcomes recorded in patients with diabetes mellitus (SAVOR)-TIMI 53 study. Presented at the European Society of Cardiology Congress; August 30-September 3; 2013; Amsterdam, The Netherlands. Available from: http://www.escardio.org/ about/press/esc-congress-2013/press-conferences/Documents/slides/ bhatt.pdf. Accessed September 25, 2013.

87. Hocher B, Sharkovska Y, Mark M, Klein T, Pfab T. The novel DPP-4 inhibitors linagliptin and BI 14361 reduce infarct size after myocardial ischemia/reperfusion in rats. Int J Cardiol. 2013;167(1): 87-93.

88. Chaykovska L, von Websky K, Rahnenführer J, et al. Effects of DPP-4 inhibitors on the heart in a rat model of uremic cardiomyopathy. PLoS One. 2011;6(11):e27861.

89. Shah ND, Mullan RJ, Breslin M, Yawn BP, Ting HH, Montori VM Translating comparative effectiveness into practice: the case of diabetes medications. Med Care. 2010;48(Suppl 6):S153-S158.

90. Spencer MS, Kieffer EC, Sinco BR, et al. Diabetes-specific emotional distress among African Americans and Hispanics with type 2 diabetes. J Health Care Poor Underserved. 2006;17(Suppl 2):88-105. 
91. Drucker DJ, Buse JB, Taylor K, et al; DURATION-1 Study Group. Exenatide once weekly versus twice daily for the treatment of type 2 diabetes: a randomised, open-label, non-inferiority study. Lancet. 2008;372(9645):1240-1250.

92. Boehringer Ingelheim Pharmaceuticals. Safety and efficacy in type 2 diabetic patients with severe chronic renal impairment, $5 \mathrm{mg}$ BI 1356 (Linagliptin) vs placebo, insulin background inclusive. Available from: http://www.clinicaltrials.gov/ct2/show/NCT00800683?term=NCT00800 683\&rank=1. NLM identifier: NCT00800683. Accessed May 29, 2013.

93. Boehringer Ingelheim Pharmaceuticals. Efficacy and safety of linagliptin in elderly patients with type 2 diabetes. Available from: http://www. clinicaltrials.gov/ct2/show/NCT01084005?term $=$ NCT01084005\&ran k=1. NLM identifier: NCT01084005. Accessed May 29, 2013.

94. Buse JB, Henry RR, Han J, Kim DD, Fineman MS, Baron AD; Exenatide-113 Clinical Study Group. Effects of exenatide (exendin-4) on glycemic control over 30 weeks in sulfonylurea-treated patients with type 2 diabetes. Diabetes Care. 2004;27(11):2628-2635.

95. Lewin A, Lipetz R, Wu J, Schwartz S. Comparison of extended-release metformin in combination with a sulfonylurea (glyburide) to sulfonylurea monotherapy in adult patients with type 2 diabetes: a multicenter, double-blind, randomized, controlled, phase III study. Clin Ther. 2007;29(5):844-855.

96. ONGLYZA ${ }^{\circledR}$ (saxagliptin) tablets [package insert]. Princeton, NJ: Bristol-Myers Squibb; 2011.
97. JANUVIA ${ }^{\circledR}$ (sitagliptin) tablets [package insert]. Whitehouse Station, NJ: Merck Sharp and Dohme Corp; 2006.

98. Kothny W, Foley J, Kozlovski P, Shao Q, Gallwitz B, Lukashevich V. Improved glycaemic control with vildagliptin added to insulin, with or without metformin, in patients with type 2 diabetes mellitus. Diabetes Obes Metab. 2013;15(3):252-257.

99. Rosenstock J, Rendell MS, Gross JL, Fleck PR, Wilson CA, Mekki Q. Alogliptin added to insulin therapy in patients with type 2 diabetes reduces $\mathrm{HbA}(1 \mathrm{C})$ without causing weight gain or increased hypoglycaemia. Diabetes Obes Metab. 2009;11(12):1145-1152.

100. Inzucchi SE, Nauck M, von Eynatten M, Hehnke U, Woerle HJ, Henry R. Lower risk of hypoglycemia in elderly type 2 diabetes patients when linagliptin is added to basal insulin: an exploratory analysis. Poster presented at the 73nd Scientific Sessions of the American Diabetes Association; June 21-25, 2013; Chicago, IL.

101. Ahrén B, Schweizer A, Dejager S, et al. Vildagliptin enhances islet responsiveness to both hyper- and hypoglycemia in patients with type 2 diabetes. J Clin Endocrinol Metab. 2009;94(4):1236-1243.

102. Nauck MA, Heimesaat MM, Behle K, et al. Effects of glucagonlike peptide 1 on counterregulatory hormone responses, cognitive functions, and insulin secretion during hyperinsulinemic, stepped hypoglycemic clamp experiments in healthy volunteers. J Clin Endocrinol Metab. 2002;87(3):1239-1246.
Vascular Health and Risk Management

\section{Publish your work in this journal}

Vascular Health and Risk Management is an international, peerreviewed journal of therapeutics and risk management, focusing on concise rapid reporting of clinical studies on the processes involved in the maintenance of vascular health; the monitoring, prevention and treatment of vascular disease and its sequelae; and the involvement of

\section{Dovepress}

metabolic disorders, particularly diabetes. This journal is indexed on PubMed Central and MedLine. The manuscript management system is completely online and includes a very quick and fair peer-review system, which is all easy to use. Visit http://www.dovepress.com/ testimonials.php to read real quotes from published authors. 